\title{
FOETAL ASCITES
}

\author{
BY \\ JOSEPHINE M. LORD \\ From The Institute of Child Health, Hammersmith Hospital, London
}

(RECEIVED FOR PLBLICATION MAY 18, 1953)

The term 'foetal ascites' is customarily used to describe ascites unaccompanied by generalized oedema, occurring either during intra-uterine life or shortly after birth. The condition is generally ascribed in textbooks of paediatrics to congenital syphilis. Donald (1949) stated that the ascites is due to some pyogenic infection to which the syphilitic baby is susceptible. According to Paterson and Twistington Higgins (1933) either chronic inflammation of the peritoneal cavity accompanying syphilis or congenital malformations can be aetiological factors in foetal ascites. In an experience of over $\mathbf{8 , 0 0 0}$ young babies, I have seen only two cases of ascites, both associated with an obstruction of the lower urinary tract. It is to the existence of this generally neglected connexion between foetal ascites and congenital urinary obstruction that I wish to draw attention.

\section{Case Reports}

Case 1. A boy of 5 weeks was referred to the County Hospital, Hereford, on August 21, 1946, with a diagnosis of marasmus. The mother stated that he had been ill for four days only, with a cough and constipation (frequent, hard motions). On questioning, she agreed that the abdomen was prominent, and thought that this enlargement had occurred 'since the baby was ill'. No abnormality of micturition had been noticed.

He was her first child, and the delivery had been normal. He was born at home, the birth weight being $6 \mathrm{lb} .12 \mathrm{oz}$. He was breast fed for two weeks, then given artificial feeds. He took fluids well, but vomited once before admission. During the last week he had lost $11 \mathrm{oz}$. in weight.

On admission he was an emaciated, angry baby. The abdomen was grossly distended with fluid, and there was oedema of the abdominal wall, but none elsewhere. He was neither dehydrated nor anaemic. Bilateral reducible inguinal herniae were present, and bilateral hydrocoeles. No solid organs or masses could be palpated within the tense abdomen. There were signs of atelectasis at the right lung base, and a radiograph of the chest showed poor aeration of both bases. The abdomen was tapped with a Southey's tube and a pint of clear, straw-coloured fluid drained. A mass could then be palpated in the right loin. The left kidney was not clinically enlarged.
The ascitic fluid soon reaccumulated, and two days after admission a laparotomy was performed by $\mathbf{M r}$. Wood Power, who found gross enlargement of the bladder and an enlarged right kidney. No further exploration was made and the abdomen was closed.

The ascites increased, respiration became embarrassed, and the child died four days after admission.

At necropsy some degree of hydronephrosis on the left, and a gross right hydronephrosis were found accompanying the ascites. There were bilateral megaureters, and the bladder was enlarged up to the umbilicus. There appeared to be some obstruction at the ureterovesical junctions. The specimen was placed in fixative before examination of the urethra, and was then unfortunately lost. It was suggested that the abdominal fluid might be urine which had leaked out from the tense right kidney.

Case 2. A full term boy weighing $9 \mathrm{lb} .15 \mathrm{oz}$. was delivered at Hammersmith Hospital on November 18, 1951. The mother was apparently fit, had had one previous normal child, and has since had a normal infant. There was difficulty in this delivery due to the size of the foetal abdomen, and the child was shocked at birth. Respiration started at ten minutes when endotracheal oxygen was administered, but the baby continued to show signs of atelectasis. He had signs of ascites causing enormous distension of the abdomen. There was a little oedema of the scrotum, but no generalized oedema or anaemia. No organs or tumours could be felt within the tense abdomen. One drop of fluid was noticed at the tip of the penis just before death. No other abnormalities were found, and he did not show the 'potter's facies'.

The placenta weighed $2 \mathrm{lb}$. The mother's blood was Wassermann negative, Kahn negative, $R h$ positive. The cord blood was Coombs negative.

He died at $1 \frac{1}{2}$ hours of asphyxia. A post-mortem examination was made by Dr. B. Lennox, whose findings are summarized as follows:

Cardiovascular System. Normal.

Central Nervous System. Normal.

Respiratory System. Partial atelectasis.

Alimentary System. Gastro-intestinal tract normal.

The peritoneal cavity contained $750 \mathrm{ml}$. of clear, straw-coloured fluid. The peritoneum appeared normal. The tissues of the posterior abdominal wall were markedly oedematous, but here no actual communication with the peritoneal cavity was demonstrated.

GeNito-URINARY SYSTEM. Both kidneys were markedly 
hydronephrotic, the right more than the left. The left measured $45,25 \mathrm{~mm}$.: the pelvis was dilated, and the kidney around was reduced in thickness but retained much of its normal pattern. The right kidney measured $60.40 \mathrm{~mm}$. The renal pelvis was a mere bag surrounded by a $4 \mathrm{~mm}$. shell of largely structureless renal tissue. It contained several cysts, of which one at least was cut into on removing the kidney. It was not certain whether this represented an actual communication between the kidney and the perinephric fat, or if it was an artefact.

Both ureters were grossly distended and elongated, the right averaging $20 \mathrm{~mm}$. and the left $9 \mathrm{~mm}$. in diameter. Both were normally connected to the bladder, but a communication could not be demonstrated by probing, nor by the injection of fluid, probably because of the contracted state of the hypertrophied bladder.

The bladder was empty but very thick-walled, forming a nearly spherical mass $28 \mathrm{~mm}$. in diameter even when empty, and its wall averaged $6 \mathrm{~mm}$. in thickness. The trigone appeared normal. The prostatic urethra was distended. On passing a probe upwards through the urethra it could be seen from above to run for a short distance within a longitudinal fold which ran downwards from the verumontanum to open finally at the upper end of this fold immediately below the verumontanum as a narrow, $3 \mathrm{~mm}$.-long vertical slit. Although a normal probe could be made to pass through this slit, the structure would act as a valve (Figs. 1 and 2).

The right kidney was severely damaged with complete loss of most nephrons. There was fibrosis but no inflammation. No major damage was seen in the left kidney.

The cause of the hydronephrosis was thought to be a valvular obstruction of the prostatic urethra.

Both these infants had ascites, bilateral hydronephrosis, with gross destruction of renal tissue on the right side only, bilateral mega-ureter, and dilatation and hypertrophy of the bladder-all apparently due to an obstruction of the lower urinary tract. The ascitic fluid was not examined chemically. No communication between the kidneys and the peritoneal cavity was demonstrated. In the

second case the appearance of the right kidney and the posterior abdominal wall was compatible with a leak of urine. No other cause for the ascites was found in either case.

The diagnosis in the second case was suspected from analogy with the first case.

\section{The Literature on Foetal Ascites}

Fordyce in 1894 collected 63 examples of foetal ascites, including 46 cases in which a necropsy was performed. The most frequent finding was evidence of peritonitis shown by thickening of the peritoneum, adhesions, and flakes of lymph or fibrinous exudate. Other pathological findings, often accompanying peritonitis, were recorded in 31 cases:

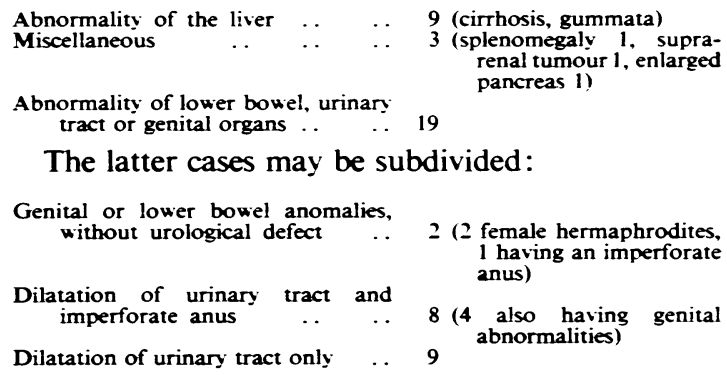

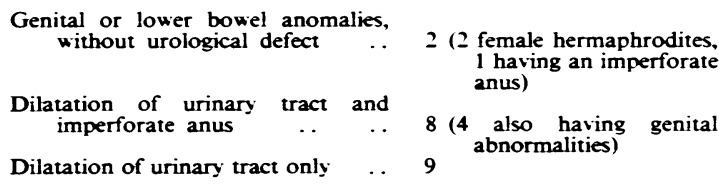

2 ( 2 fernale hermaphrodites, 1 having an imperforate anus) 9

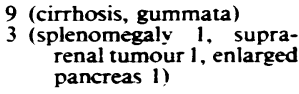
renal tumour 1, enlarged pancreas 1)

Fordyce disproved the prevalent notion that foetal ascites was due to syphilis. He found evidence of parental syphilis in only nine of his 63 cases. He stressed the findings of an enlarged bladder in 16 cases, but did not state the sex of his patients.

The significance of distension of the bladder was acknowledged by Birnbaum and Blacker (1912) but attributed to syphilis, and this opinion has been reiterated by later writers (Hunter, 1932).

Dorland (1919) is now the most frequently quoted authority on foetal ascites. He believes that 'true' foetal ascites is due to peritonitis, but he emphasizes

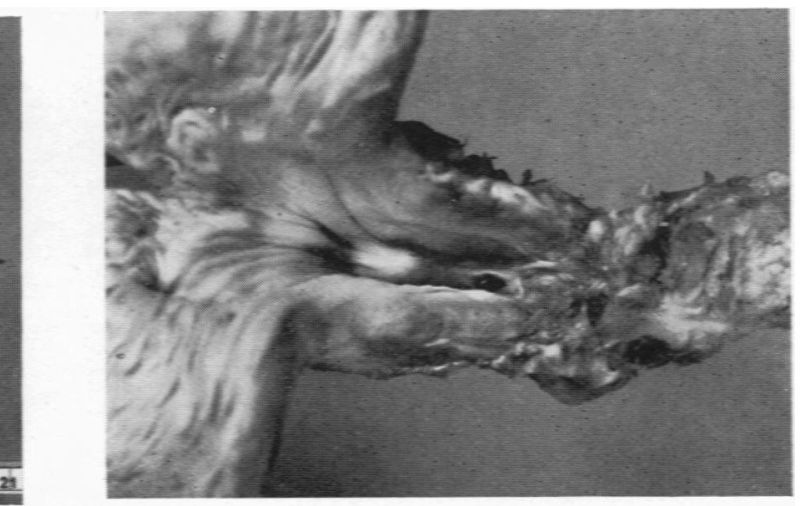

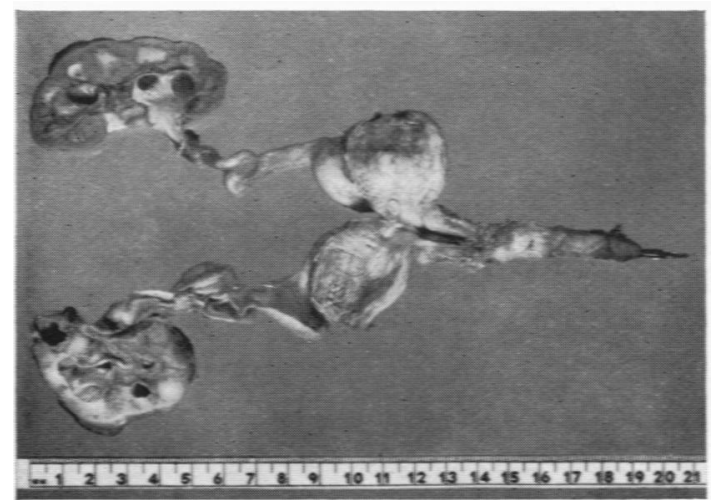

Figs. 1 and 2.-Urethral valve in an infant with ascites. 
the importance of congenital lesions in other types. He describes six types of watery accumulation in the peritoneal cavity: (1) Accumulation of serum in the foetal peritoneal cavity - 'true foetal ascites', (2) a collection of fluid distending the urinary tract of the foetus-'retention of foetal urine', (3) a collection of fluid in the tissues of the foetal body- 'general anasarca', (4) cystic degeneration of the renal structures of the foetus-'congenital polycystic kidney', (5) cystic degeneration of the foetal liver, (6) fluid distension of the genital tract of the foetus - vagina, uterus and tubes.

Dorland's Group 1 consists chiefly of cases of foetal peritonitis. Group 3 may here be omitted. His Group 6 consists of two cases in which distension of the genital tract was associated with imperforation of the anus. In his four instances in Group 5 there is accompanying renal tract abnormality. Discussing Group 4, he states that the polycystic kidney is commonly associated with dilatation of the ureters and bladder. It is likely that in the nineteenth century cases he quotes there is no clear differentiation between hydronephrosis and polycystic kidney. Many of the references he gives concern tumours and cysts that presented as a differential diagnosis from ascites, but did not in fact accompany foetal ascites. Most of the cases in Groups 4, 5 and 6 can be considered with Group 2 as cases of retention of foetal urine.

Previous writers on foetal ascites do not mention the sex of their patients, a factor of major importance in the diagnosis and treatment of abnormalities of the urinary system.

The more accessible reports are therefore reviewed here to determine the sex incidence, and what proportion of the cases are associated with lesions of the urinary tract.

\section{Discussion}

Syphilis. Syphilitic cirrhosis can cause foetal ascites, as in the cases mentioned by Fordyce (1894). Champeau (1933) records a case where the abdominal enlargement was chiefly due to hepatomegaly. There was only $60 \mathrm{ml}$. of ascitic fluid.

Hunter (1932) believed syphilis to be responsible for the congenital defects and the ascites in his case of persistent cloaca. Unexplained cases of ascites continue to be attributed to this infection. Pinto

REVIEW OF CASES OF ASCITES

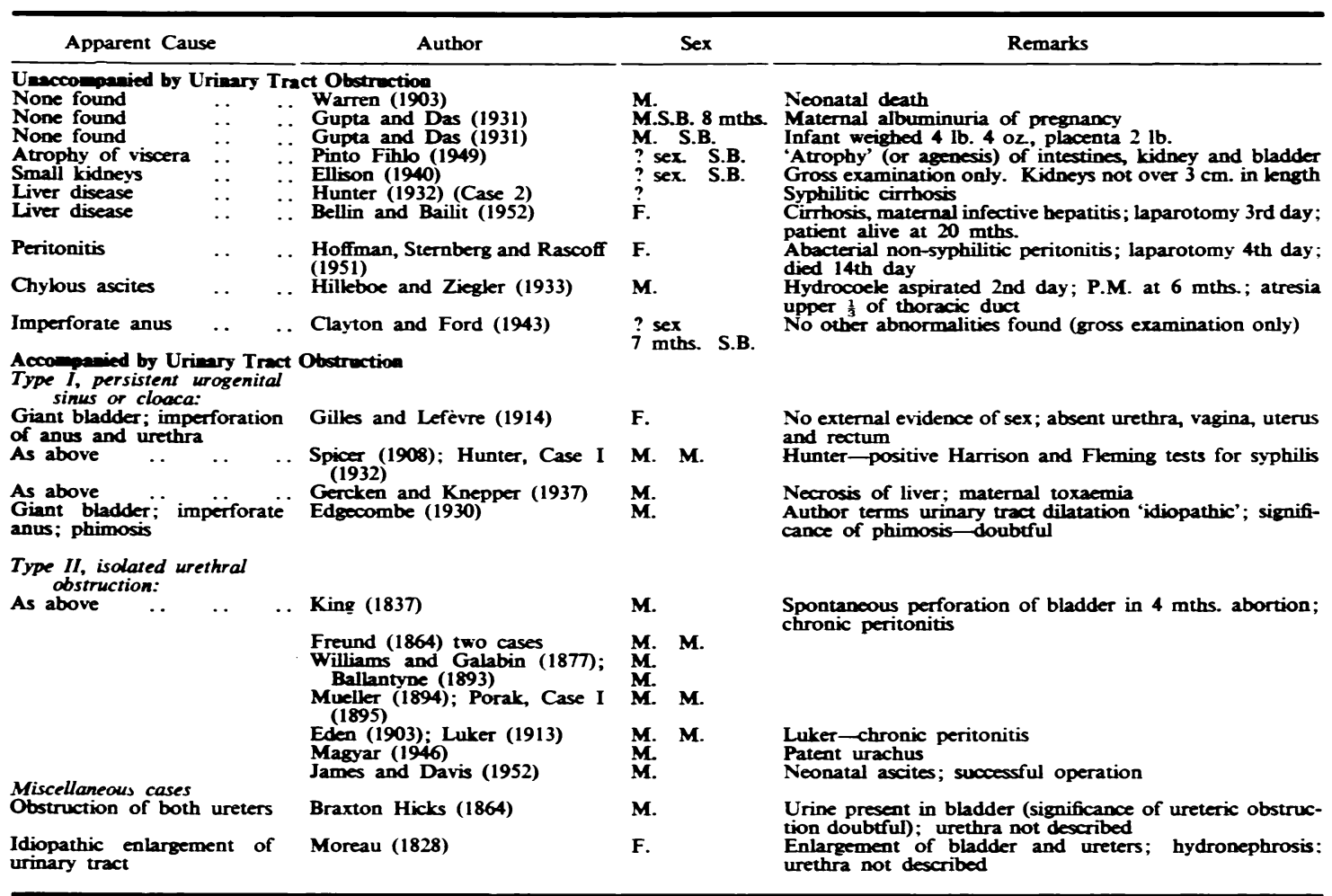

$$
\text { M. }=\text { Male. } \quad \text { F. }=\text { Female. } \quad \text { S.B. }=\text { Stillborn. }
$$


Fihlo (1949) thus explains his case of atrophy of the viscera, on the evidence only of the mother's previous miscarriages. Most cases of ascites in which there was no internal examination of the foetus have been presumed to be syphilitic (Ricard, 1932: Brando, 1934) without proof of maternal syphilis.

Peritonitis accompanying congenital syphilis is a rare cause of ascites. No convincing report of syphilis with intra-uterine peritonitis has been given since that of Apert (1895). Cruickshank (1930) reports the finding in dead syphilitic infants of visceral fibrosis, not ascites.

Other Causes. No example has been found of the association of polycystic kidneys and pure ascites. In one case (Hunter, Case 4) there was generalized oedema.

Chylous ascites is not here under consideration. In the remaining 27 cases in this series an identified pathological finding together with ascites is described in 22 cases. Cirrhosis or peritonitis was present in three instances, and a congenital malformation in 19 , of which 18 showed urinary obstructive lesions.

There remains one case of isolated imperforation of the anus, which may be compared with the three female infants having genital abnormalities and imperforation, described respectively by Fordyce and Dorland, and five cases of obscure origin.

Aetiology of Ascites not Associated with Urinary Obstruction. Various theories have been advanced to explain ascites not associated with urinary obstruction. Dorland lists defects in the circulatory apparatus of the foetus, compression of the large vessels by abdominal tumours, foetal circulatory failure and hypofunction of the urinary apparatus.

There is no evidence that heart failure causes pure ascites. Obstruction of the portal circulation by a tumour or congenital defect has not been incriminated recently. Hunter (1932) in his Case 3 describes splenomegaly (a finding previously quoted by Fordyce) together with hypoplasia of the splenic and portal veins. The infant had generalized oedema.

Hypofunction of the urinary apparatus is an unlikely cause of foetal ascites, since most infants having no kidneys appear normal at birth. On naked-eye examination, the kidneys in Ellison's foetus were small, and in Pinto Fihlo's case there was 'atrophy' of both the renal system and the intestines, whether primary or resulting from the increased intra-abdominal tension. This 'atrophy' of organs may in fact be agenesis. Accumulation of fluid in the abdomen or in other affected areas occurs in rudimentary foetuses. Alam (1922) reports the occurrence of ascites and hydrothorax in a foetus having no thoracic, lumbar or sacral vertebrae. The diaphragm was present, but the only thoracic or abdominal organs were a heart and a loop of gut.

Finally, localized circulatory embarrassment may be the cause of the intra-uterine ascites in cases of intestinal obstruction and imperforate anus.

Thus, on the present evidence, foetal ascites in the absence of urinary obstruction occurs in the following rare conditions: cirrhosis, foetal peritonitis of unknown aetiology, agenesis of intra-abdominal organs, and imperforation of the anus.

Ascites and Urinary Tract Obstruction. Dilatation of the urinary passages was found in 18 cases, and in 17 of these an obstructive lesion is described. Amongst these, there is one case in which the pathological lesion seems inconclusive. Braxton Hicks ( 1864) believed that in his case hydronephrosis was due to bilateral ureteric occlusion, but there was urine in the bladder, and the urethra was apparently not examined. Ureteric obstruction was simulated in my own two cases, probably owing to the contracted state of the hypertrophied bladder. One wonders if the true lesion in the case of Braxton Hicks was a urethral valve.

In one female foetus (Moreau, 1828) ascites and general dilatation of the urinary tract without demonstrable obstruction were found. A similar urinary condition in the female foetus, but without ascites, has been described by Rayner (1892) and by Couvelaire (1900). More recent evidence is required before accepting idiopathic dilatation of the urinary tract as a cause of foetal ascites in either sex.

Obstruction of the urethra is recorded in 16 cases. In five of these (which may be classed as type I) there was imperforation of the anus, associated usually with atresia of the urethra, but in one case with phimosis. The rectum terminated in a cul-desac behind the giant bladder, or persistent urogenital sinus. In two of these cases there was a persistent cloaca, the rectum communicating by a narrow opening with the giant bladder. Hydronephrosis was usually gross, although occasionally unilateral. The volume of fluid in the bladder was much greater than the amount of ascitic fluid. In fact, in many cases of this malformation, in which no mention is made of ascites, the size of the foetal abdomen is entirely due to the enlargement of the bladder, as in Cruickshank's case (1921), and others collected by Spicer (1908). Where imperforation of the urethra and anus coexist the malformation is complex and the prognosis usually hopeless.

Ascites and isolated urethral obstruction occurred in 11 cases, all male. These may be termed type II. 
In King's case, a four months' abortion, spontaneous perforation of the bladder had occurred. Chronic peritonitis was found in this case, and in the case of Luker. Mega-ureters and hydronephrosis were common but not constant. Thus Eden (1903) found normal ureters and kidneys, and Luker (1913) found mega-ureters but normal kidneys. The sites of the urethral strictures are not well described, being at the neck of the bladder in Galabin's case and in the pars membranacea in the cases of King and Magyar. The prostate was absent in the case of Mueller. A urethral valve was described by Porak in 1895 .

Most of the cases were of stillborn foetuses. They were published on account of the grossness of the abdominal distension and the difficulty experienced in delivery. They may therefore give an excessively gloomy picture of the prognosis. One case only was published for its paediatric interest (James and Davis, 1952). This baby suddenly developed ascites when 3 weeks old. Paracentesis was performed, followed by treatment for an obstruction of the posterior urethra. At 8 months there were no signs of urethral obstruction or renal inadequacy, and only slight dilatation of the renal pelves.

Origin of Ascites in Urinary Tract Obstruction. The belief of Fordyce and others that the enlargement of the bladder was secondary to chronic peritonitis cannot be upheld. Signs of peritonitis are often wanting, and when present may be secondary to the ascites.

As stated above, there is no evidence that hypofunction of the damaged kidneys causes foetal ascites, while pressure on the great vessels by the distended bladder is an improbable cause.

The relationship of ascites and urinary lesions is variable. Urethral imperforation does not necessarily cause dilatation of the foetal urinary tract according to Spicer (1908), who quoted cases in which distension of the bladder did not occur until more than 24 hours after birth, and the infant recovered following operation. Moreover, when intra-uterine dilatation of the urinary tract does occur, there may be no ascites, as in the case of Hess (1938).

Spicer attempted to explain such findings. The foetus he described had a single umbilical artery. He suggested that the volume of urine excreted by the foetal kidneys was in inverse proportion to the efficiency of placental exchange. A combination of placental insufficiency and urethral obstruction would cause enlargement of the bladder. According to this theory, there is hyperfunction of the kidneys.

However this may be, leakage or exudation of urine from the bladder, ureters or kidneys seems to be the most plausible cause of foetal ascites. In my own first case and in the case of James and Davis, ascites seems to have developed fairly rapidly after birth. In other cases it has been present in aborted foetuses. In many cases, hypertrophy of the bladder was interspersed with areas of thinning, and in some, including my own, the kidneys contained thinwalled cysts. Ascites may well be determined by the tension of the fluid in the urinary tract, the amount of fluid exuding being in excess of what can be absorbed through the peritoneum. The dilute urine of foetal life might leak for a prolonged period without causing an inflammatory peritoneal reaction.

The writers quoted by Fordyce (1894) and other old writers found either absent or minimal urea in the fluid both from the dilated bladders and from the peritoneum. Modern quantitative biochemical analysis would be interesting.

McCance and Widdowson (1953) have shown that the urine formed by the foetus in the earlier stages of gestation has probably the same characteristics as that formed just before term and passed at delivery. This is a hypotonic fluid with a very low urea content, a low concentration of chloride and sodium, and minimal phosphorus. Compared with the cord blood, the urine:plasma ratios of urea, chloride and sodium of normal infants averaged respectively $5,0.39$ and 0.32 . The urea content of the urine averaged $17 \mathrm{~m} . \mathrm{mol}$. per litre, or approximately 0.1 g. per $100 \mathrm{ml}$. compared with the usual adult figure of $2 \mathrm{~g}$. per $100 \mathrm{ml}$. The foetal urine contained more sodium than chloride.

It follows that if the abdominal cavity of a newborn infant contained unmodified foetal urine, one would expect a hypotonic fluid containing about five times as much urea per $100 \mathrm{ml}$. as the infant's blood.

Unlike the ascitic fluid of the cirrhotic adult. (Bodapsky and Bodansky, 1940) the baby's peritoneal fluid might contain more sodium than chloride. However, such a fluid would be in contact with the mesenteric blood supply and one would expect equilibration with the extracellular fluids to result, which would considerably modify the chemical constitution.

The most rapidly developing ascites appears to be that which occurs during extra-uterine life in an infant with urethral obstruction, but here, too, even though the fluid was originally urine, equilibration would probably be so rapid that the fluid examined would tend to have the composition of extracellular fluid rather than of foetal urine.

Analysis of the ascitic fluid from cases of foetal and infantile ascites would therefore be interesting but probably not diagnostic. 


\section{Summary}

Foetal and neonatal ascites is usually ascribed in textbooks of paediatrics to congenital syphilis. This has in fact become a rare cause of the condition.

Two cases are here reported of ascites associated with obstructive lesions of the lower urinary tract. Both patients were male, one being 5 weeks old when the diagnosis was made, and the second newborn. The diagnosis was suspected in the second patient, but unfortunately he died of atelectasis before the ascites could be relieved.

A study of the literature shows that ascites may occur in cases of cirrhosis, foetal peritonitis, agenesis of intra-abdominal organs and imperforation of the anus. Congenital obstruction of the urethra is the most common cause of foetal and neonatal ascites. Two main types occur. In the first there is an associated malformation of the anus, and the urinary tract abnormality is gross and the prognosis poor. In the second, and apparently commoner type, there is an isolated urethral obstruction in the male, and prompt surgical treatment may be effective. Success in one such case has been reported. Once suspected, the diagnosis is easy to establish, and it is important that this cause of foetal ascites should be recognized.

I wish to thank Mr. P. Brown, Professor J. McClure Brown and Professor A. A. Moncrieff for permission to publish the cases, and I am grateful to Professor R. A. McCance and Miss E. M. Widdowson for giving me access to the work on the composition of foetal urine.

REFERENCEs
Alam, M. (1922). Indian med. Gaz., 57, 260.
Apert. E (1895) Bull Soc Anat Paris 70, 545.

Ballantyne. J. W. (1893). Edinb. Hosp. Rep., 1. 612.

Bellin, L. B. and Bailit, I. W. (1952). J. Pediat., 40.60.

Birnbaum, R. and Blacker, G. (1912). A Clinical Manual of the Malformations and Congenital Diseases of the Fostus, p. 184. London.

Bodansky, M. and Bodansky, O. (1940). Biochemistry of Disease, p. 250 . New York

Brando, P. (1934). Rev. Gynec. Obstet., Rio de J., 28. 181

Champeau, J. (1933). in med. Can., 62. 549

Clayton, J. W. and Ford, R. M. (1943). Med. J. Aust., 1. 537.

Couvelaire, - (1900). Bull. Soc. anat. Paris, 75, 287.

Cruickshank, J. N. (1921). Brit. med. J., 2. 980.

(1930). Spec. Rep. Ser. med. Res. Coun. (Lond.) 145.

Donald, C. (1949). In Garrod. Batten and Thursfield's Diseases of Children, 4th ed., ed. D. Paterson and A. Moncrieff, vol. 2. p. 557. London.

Dorland, W. A. N. (1919). Amer. J. Obstet. Dis. Hom., 79, 474.

Eden, T. W. (1903). Trans. obstet. Soc. Lond., 45. 45.

Edgecombe, K. (1930). J. Obstet. Gynaec. Brit. Emp., 37, 832.

Ellison, E. T. (1940). Amer. J. Obstet. Gynec., 40, 1057.

Fordyce, W. (1894). Teratologia, 1, 61, 143.

Freund, M. B. (1864). In J. W. Betschler and W. A. Freund Klinische Beiträge zur Gynäkologie, heft 2. p. 240. Breslau.

Gercken, F. and Knepper, R. (1937). Zbl. Gynäk., 61, 710

Gilles, Roques and Lefévre (1914). Bull. Soc. Obstét. Gynec. Paris, $17,148$.

Gupta, N. and Das, P. C. (1931). Indian med. Gaz., 66, 186.

Hess, E. (1938). J. Urol., 39, 817.

Hicks, J. Braxton (1864). Trans. obstet. Soc. Lond., 5, 285.

Hilleboe, H. E. and Ziegler, M. R. (1933). Amer. J. Dis. Child., 46. 928 . Hoffman, C., Sternberg, S. D. and Rascoff, H. D. (1951). Ibid.,

Hunter, R. H. (1932). Lancet, $2,999$.

James, U. and Davis, J. A. (1952). Proc. roy. Soc. Med., 45, 401.

King. T. W. (1837). Guy's Hosp. Rep., 2 (1st ser.), 508.

Luker, S. G. (1913). Lancet, 1. 1309.

Magyar, K. (1946). Gynaecologia, 122, 363.

McCance, R. A. and Widdowson, E. M. (1953). Renal Function Before Birth. (In the press.)

Mueller, A. (1894). Arch. Gynäk., 47, 130.

Moreau (1828). Arch. gén. Med., 17, 299.

Paterson, D. and Higgins, T. Twistington (1933). In L. G. Parsons and $S$. Barling Diseases of Infancy and Childhood, vol. 1, pp. 822-3. London.

Pinto Filho B (1949). Rev. Ginec Obstet., Rio de J., 2498.

Porak (1895). J. Med. Paris, sér. 2, 7, 392

Rayner, W. (1892). Brit. med. J., 2 , 1384.

Ricard, A. (1932). Un. méd. Can., 61, 596.

Spicer, J. E. (1908). Proc. roy. Soc. Med., 2, Obstet. Gynaec Sect., p. 1.

Warren, S. P. (1903). Amer. J. Dis. Wom., 48, 173.

Williams, J. and Galabin, A. L. (1877). Trans. obstet. Sac. Lond., $19,120$. 